\title{
A Survey of Chinese Engineering Students' Attitudes toward EMI
}

\author{
Haiyun $\mathrm{Gu}^{\mathrm{a}}$, Lei Ren
}

School of Information Engineering, Shanghai Maritime University, Shanghai 210306, China;

ahygu@shmtu.edu.cn, bleiren@shmtu.edu.cn

Keywords: EMI, Chinese engineering education, students' attitudes.

\begin{abstract}
EMI (English as a Medium of instruction) has been officially promoted in Chinese universities for 15 years. This paper reports a survey of Chinese engineering students' attitudes toward EMI. It starts by presenting the necessity for engineering students to learn their major subjects in english. A group of 50 sophomores and 50 juniors, majoring in telecommunication engineering and electronic engineering, were surveyed using a 20-item questionnaire about their attitudes toward EMI. The analyses of results reveal that the participants quite agree with the importance of english as a working language and the promotion of EMI strategy in engineering education in Chinese universities, but they equally worry about their english proficiency might have negative effect on disciplinary learning. Finally, the paper suggests several specific measures to improve the efficiency of EMI policy in Chinese engineering education.
\end{abstract}

\section{Introduction}

According to the reports from SEVP (student and exchange visitor program) of the USA, more than 1,000,000 international students enter American universities every year. About 1/3 of these students are from china, and 38\% of them choose science and engineering specialties [1]. It is no doubt that the engineering education in America is much better than China, especially in the specialties such as Information Technology and Computer Science which are originated from the USA.

English is a world language [2].In order to keep up with the rapid development of this information era, Chinese Ministry of Education has attached much significance to the introduction of english classic textbooks, and promoted the EMI policy in chinese higher education for about 15 years [3]. Many research works have been done about EMI in Chinese Universities, including the curriculum setting, teaching methodology and efficiency, studying environment, teachers' training, and etc [4-6].

Nowadays, Internet provides students easy access to massive open online courses [7-10]. There are even many simulation tools and experimental software which can be downloaded easily to help with the study of engineering courses. Students' requirements to the classroom education could be greatly changed. This paper is the first study that aims to the chinese engineering students' attitudes toward EMI. The analyses of the survey results provide implications for policy-makers.

\section{Method}

\subsection{Research setting.}

Our university is located in Shanghai which is a technologically advanced city in IT business. We had run EMI courses for nearly 10 years, with an average of 33 courses per semester.

The authors designed a direct attitude questionnaire of 20 items based on the teaching experiences of classroom education. The questionnaire was administered anonymously during an EMI major course period in the second semester of the 2015-2016 academic year. A group of 50 sophomores and 50 juniors, majoring in telecommunication and electronic engineering, volunteered to respond to the 20 statements on a four-level scale ranging from strong agreement to strong disagreement $(\mathrm{A}=$ strong agreement, $\mathrm{B}=$ agreement, $\mathrm{C}$ = disagreement, $\mathrm{D}=$ strong disagreement). Following is a profile of the survey participants: 
Table 1 Survey Participants’ Profiles

\begin{tabular}{|c|c|c|c|}
\hline Grade & Amount & Age & Study Program \\
\hline Sophmore & $22 \mathrm{M} / 28 \mathrm{~F}$ & $19-21$ & Specialized english \\
\hline Junior & $23 \mathrm{M} / 27 \mathrm{~F}$ & $20-22$ & $\begin{array}{l}\text { Specialiaed english, network } \\
\text { communication, database, DSP }\end{array}$ \\
\hline
\end{tabular}

\subsection{Questionnaire.}

Although the participants in our survey are non-english major students, they are required to pass College English Test (CET) Band 4 before graduation [11]. So, they must take english courses when they were freshmen. In their senior year, most of them will work as interns in IT companies. In order to get a whole view, we designed a questionnaire including 20 items to survey their attitudes to the english studying, the professional english studying, the specialized english textbooks and papers, the english version specialized software, and the english exam of major course. The 20 items are:

1) I learn english just because I want to pass examinations.

2) I would learn english even if it were not a compulsory course in university.

3) Listening and speaking training should be strengthened in College English class.

4) My english is getting worse since I entered the college.

5) I feel uncomfortable when hearing two chinese speaking english to each other.

6) I like to speak english with foreigners.

7) Chinese people should learn english because it is a world language.

8) If I speak fluent english, I will find better jobs.

9) English proficiency represents a person's level of education.

10) It is necessary for engineering students to take a professional english course.

11) Electronic engineers should have good english skills.

12) Electronic and computer major courses should choose foreign classic textbooks.

13) The chinese version of foreign classic textbook is easier to read.

14) The meaning of technical term is clearer in english.

15) English version of the professional software is more difficult to use.

16) The difficulty of EMI courses is lower than that of chinese courses.

17) I want to learn the open online courses of foreign schools.

18) I'd like to take a major course in english.

19) EMI is conducive to the domestic diploma recognized by other countries.

20) EMI should be actively promoted in chinese engineering education.

\section{Data Collection and Analysis}

\subsection{Survey results of 1)-9) items.}

1)-9) items are mainly about the engineering students' attitudes to college english courses and the impact of english proficiency. As shown in Figure 1:

$\checkmark$ 92\% of participants agree that Chinese should learn English. 84\% of participants believe that fluent english will be a great help to the future career. But $60 \%$ of them don't consider the english proficiency represents a person's level of Education.

$\checkmark \quad 20 \%$ of participants hold a negative attitude to college english courses. $75 \%$ of participants think their english ability is not as good as before. Nearly all of them consider the listening and speaking training should be strengthened in college english classes. 


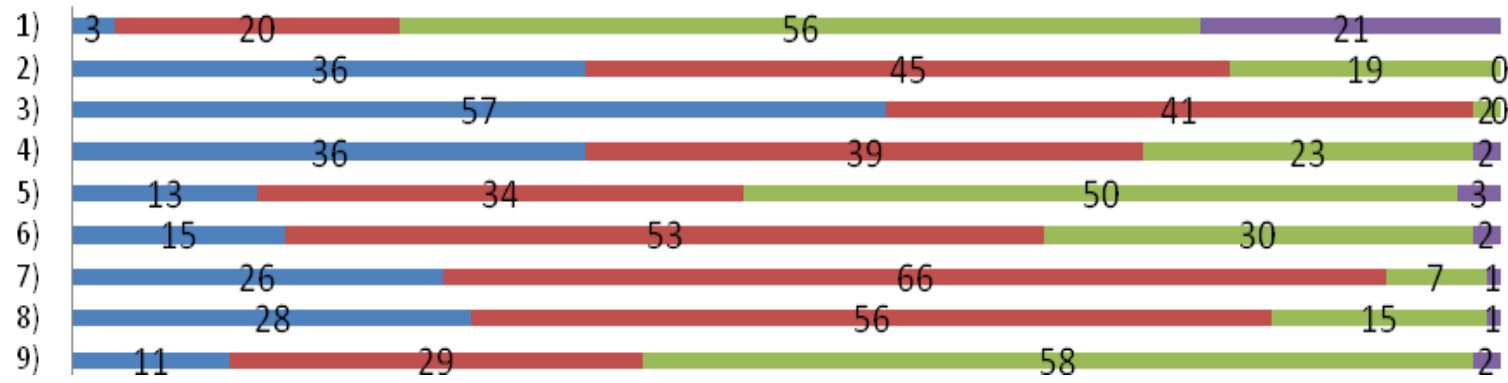

Fig. 1 Survey Results of 1)-9) items

The above results indicate that there is no dispute about the importance of english studying. But after nearly 10 years of learning english at primary and secondary schools, more than half of the engineering students still don't have good enough english skills. Policy-makers should put a stronger emphasis on practically english skills education.

\subsection{Survey results of 10)-20) items.}

10)-20) items relate to the engineering students' attitudes to the studying of specialized english, foreign classic textbooks and professional software. As shown in Figure 2:

\section{- Strong Agreement $\quad$ Agreement $\quad$ Disagreement $\quad$ Strong Disagreement}

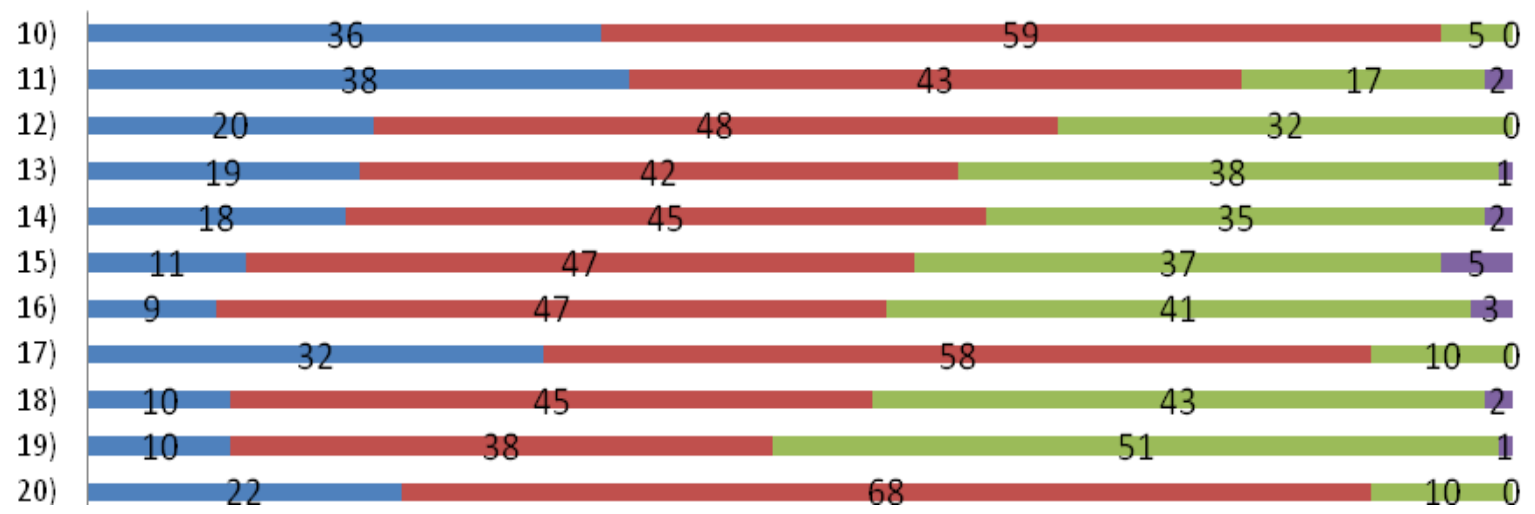

Fig. 2 Survey Results of 10)-20) items

$\checkmark \quad 95 \%$ of participants think specialized english course is very necessary for the engineering students. $60 \%$ of them prefer the chinese version of foreign classic textbooks for lack of technical terms. But they admit that the meaning of the original english terms are clearer.

$\checkmark \quad 90 \%$ of participants are willing to take open online courses in engineering and english version professional developing tools. They also agree with the promotion of EMI. But for now only $55 \%$ of them are really willing to choose an EMI major course if there is a corresponding CMI course at the same time.

This part of survey results reveals the real attitudes of engineering students toward EMI. Nearly all of them have recognized that specialized english will be very helpful to the future engineer careers. The attraction of open online courses partly lies in the chinese subtitles which they can repeatedly watch if they couldn't keep up with the lectures. The main problem of open online courses is that students cannot communicate with the professors in real time. For EMI major courses in classroom education, students worried that their limited english proficiency would negatively affect the understanding of contents. 


\section{Conclusion}

In this paper, a survey on the engineering students' attitudes toward EMI has been presented. The authors designed a 20-item questionnaire, 100 engineering students volunteered in this survey. The results analyses showed that engineering students are aware of the importance of learning specialized english, studying foreign classic textbooks and using professional developing tools. The main barrier of promotion EMI in chinese engineering education is the students' fears for their english proficiency. So, our suggestion includes: 1) strengthening practical English skills training; 2) providing online videos of EMI courses; 3) providing latest technology resources for downloading; 4) providing variety of communication ways between students and teachers; 5) emphasizing the experiments and labs in engineering education.

Next step, we will deeply analyze the results of this survey, and practice different ways to improve the efficiency of EMI in engineering major course. In spite of some difficulties, we personally believe that EMI policy is necessary and feasible in chinese engineering education.

\section{Acknowledgement}

This paper is supported by Science \& Technology Program of Shanghai Maritime University.

\section{References}

[1]. Information on: www.sevp.com

[2]. Rining Wei, Jinzhi Su, Surveying the English language across China, World Englishes, Vol.34(2015) No.2, p.175-189.

[3]. Guangwei Hu, Linna Li, Jun Lei, English-medium instruction at a Chinese University: rhetoric and reality. Lang Policy (2014) 13:21-40.

[4]. Jing Chen, Problems and Countermeasures of Bilingual Teaching of Science and Engineering in Colleges and Universities, Research in Teaching, Vol.36 (2013) No.1, p. 43-44.

[5]. Jie Pan, Jing Wang, Practice and Reflection on Bilingual Teaching of Science and Engineering in Universities, Journal of Shandong Normal University (Natural Science), Vol. 23 (2008) No.4, p. 141-143.

[6]. Qingyang Wang, Yuxiang Wu, Discussion on Several Problems in Bilingual Teaching of Science and Engineering, Theory and Practice of Education,Vol. 27 (2007), p.12-14.

[7]. Information on: open.163.com

[8]. Information on: www.openke.net

[9]. Information on: open.sina.com.cn

[10]. Information on: opencla.cntv.cn

[11]. Abdulghani Muthanna, Pei Miao, Chinese Students' Attitudes towards the Use of English-medium Instruction into the Curriculum Courses: A Case Study of a National Key University in Beijing, Journal of Education and Training Studies, Vol. 3 (2015) No. 5, p. 59-69. 